\title{
WNT3A induces a contractile and secretory phenotype in cultured vascular smooth muscle cells that is associated with increased gap junction communication
}

\author{
Jon M Carthy, Zongshu Luo and Bruce M McManus
}

Evidence suggests a role for Wnt signaling in vascular wound repair and remodeling events. Despite this, very little is known about the effect of Wnt ligands on the structure and function of vascular cells. In this study, we treated vascular smooth muscle cells with $250 \mathrm{ng} / \mathrm{ml}$ of recombinant Wnt3a for $72 \mathrm{~h}$ and observed changes in the cell phenotype. Our data suggest Wnt3a completely alters the phenotype of vascular smooth muscle cells. The Wnt3a-treated cells appeared larger and had increased formation of stress fibers. These cells also had increased expression of the smooth muscle contractile proteins, calponin and smooth muscle $\alpha$-actin, and contracted a collagen lattice faster than control cells. The Wnt3a-treated smooth muscle cells displayed increased extracellular matrix synthesis, as measured by collagen I and III mRNA expression, along with increased expression of MMP2 and MMP9, but decreased TIMP2 levels. The Wnt3ainduced change in cell phenotype was associated with increased expression of the gap junction protein connexin 43. Consistent with this, Wnt3a-treated smooth muscle cells displayed enhanced intercellular communication, as measured by the scrape-loading dye transfer technique. The canonical Wnt antagonist, dickkopf-related protein 1, completely reversed the contractile protein and connexin 43 expression seen in the Wnt3a-treated cells, suggesting these changes were dependent on canonical Wnt signaling. Collectively, this data suggest Wnt3a promotes a contractile and secretory phenotype in vascular smooth muscle cells that is associated with increased gap junction communication.

Laboratory Investigation (2012) 92, 246-255; doi:10.1038/labinvest.2011.164; published online 21 November 2011

KEYWORDS: connexin 43; extracellular matrix; smooth muscle; smooth muscle $\alpha$-actin; Wnt; wound healing

Numerous studies have demonstrated that after arterial injury, vessel walls follow a response-to-injury pattern of wound healing leading to stenosis secondary to the neointimal accumulation of smooth muscle cells and extracellular matrix. ${ }^{1-4}$ A number of soluble mediators released at the site of vascular injury act as molecular cues that guide smooth muscle cell responses during repair. ${ }^{5,6}$ Growing evidence suggest a role for the Wnt family of secreted glycoproteins and their associated signaling pathways in regulating many of the processes involved in vascular wound repair and remodeling events. ${ }^{7-14}$ However, the precise mechanisms and outcomes of Wnt signaling in such settings remain unclear. Moreover, the effect of specific Wnt family members on vascular cell phenotype remain undefined.

The Wnt signaling pathway is best recognized for its role in the development of multi-cellular organisms, ${ }^{15,16}$ and is critically involved in normal heart formation. ${ }^{17}$ The Wnt family is comprised of 19 secreted glycoproteins that bind the Frizzled receptor and its co-receptor, lipoprotein receptorrelated proteins $5 / 6$, to initiate an intracellular signaling cascade that controls the turnover of $\beta$-catenin. ${ }^{18}$ In the absence of Wnt ligand, $\beta$-catenin is targeted for ubiquitinmediated degradation by the $26 \mathrm{~S}$ proteasome. However, upon ligand stimulation, canonical Wnt signaling triggers a series of phosphorylation events that lead to the accumulation of cytosolic $\beta$-catenin, which then translocates to the nucleus where it binds the T-cell factor or lymphoid enhancer-binding factor transcription factors to initiate transcription of target genes. As such, Wnt ligands can elicit a rapid and specific response in target cells.

In this study, we examined the effect of Wnt3a, a canonical Wnt ligand, on vascular smooth muscle cell morphology and

Department of Pathology and Laboratory Medicine, James Hogg Research Centre, Institute for Heart + Lung Health, University of British Columbia, Vancouver, British Columbia, Canada

Correspondence: Dr B McManus, MD, PhD, FRSC, Department of Pathology and Laboratory Medicine, St Paul's Hospital, University of British Columbia, The James Hogg Research Centre, Room 166-1081 Burrard Street, Vancouver, BC, V6Z 1Y6, Canada.

E-mail: bruce.mcmanus@hli.ubc.ca

Received 16 June 2011; revised 28 August 2011; accepted 10 October 2011 
function. Our data suggest Wnt3a stimulates a contractile and secretory phenotype in smooth muscle cells, characterized by decreased proliferation but increased expression of the contractile proteins, calponin and smooth muscle $\alpha$-actin, as well as the extracellular matrix genes, collagen I and III. The altered cell phenotype caused by Wnt3a was associated with increased expression of the gap junction protein connexin 43 and increased cell-cell communication. Use of the canonical Wnt antagonist, dickkopf-related protein 1 (DKK1), completely reversed the Wnt3a-mediated change in cell phenotype, suggesting these changes were dependent on canonical Wnt signaling. Collectively, this data suggest Wnt signaling modifies vascular smooth muscle cell phenotype and, as such, may have important implications for our understanding of vascular development and disease.

\section{MATERIALS AND METHODS Cell Culture}

Mouse vascular smooth muscle cells (ATCC, product number CRL-2797) were cultured in DMEM containing 10\% FBS and $100 \mathrm{U} / \mathrm{ml}$ penicillin/streptomycin. Cells were maintained in a humidified incubator at $37^{\circ} \mathrm{C}$ with $5 \% \mathrm{CO}_{2}$ and used for experiments between passages 6-12. Recombinant murine Wnt3a (Peprotech, product number 315-20) was added to the cells (at 50\% confluency) at a concentration of $250 \mathrm{ng} / \mathrm{ml}$ for $72 \mathrm{~h}$ before performing functional studies or collecting cells for analysis. To test that Wnt3a activated canonical Wnt signaling in the smooth muscle cells, experiments were performed where Wnt3a was only added for $24 \mathrm{~h}$ before measuring nuclear $\beta$-catenin or target gene expression. In certain experiments, transforming growth factor- $\beta$ (TGF- $\beta$; Peprotech, product number $100-21$ ) was added alone or in combination with Wnt3a at a concentration of $5 \mathrm{ng} / \mathrm{ml}$. In other experiments, recombinant murine DKK1 (R\&D systems, product number 5897-DK) was added during Wnt3a incubation at a concentration of $250 \mathrm{ng} / \mathrm{ml}$. In these experiments, cells were pretreated for $1 \mathrm{~h}$ with DKK1 before adding Wnt3a. All experiments were performed in triplicate (unless otherwise stated) and repeated a minimum of three independent times.

\section{qPCR Analysis}

RNA extraction, cDNA synthesis and qPCR analysis were performed as we have described previously. ${ }^{19}$ Predesigned primers to axin2, collagen I, collagen III, and $\beta$-actin were purchased from Applied Biosystems (assay numbers Mm00443610_m1, Mm00483888_m1, Mm01254476_m1, and Mm00607939_s1, respectively).

\section{Cell Proliferation}

Cell proliferation was measured by MTS assay (Promega) $72 \mathrm{~h}$ after Wnt3a treatment as we have described previously. ${ }^{20}$

\section{Western Blotting}

Cell lysates were collected in lysis buffer $(10 \mathrm{mM}$ HEPES ( $\mathrm{pH}$ 7.4), $50 \mathrm{mM} \mathrm{Na}{ }_{4} \mathrm{P}_{2} \mathrm{O}_{7}, 50 \mathrm{mM} \mathrm{NaF}, 50 \mathrm{mM} \mathrm{NaCl}, 5 \mathrm{mM}$ EDTA, $5 \mathrm{mM}$ EGTA, $2 \mathrm{mM} \mathrm{Na} \mathrm{VO}_{4}$, and $1 \mathrm{mM}$ phenylmethylsulfonyl fluoride, with $0.1 \%$ Triton $\mathrm{X}-100$ and $10 \mu \mathrm{g} / \mathrm{ml}$ leupeptin) followed by centrifugation at high speed $\left(14000 \times g\right.$ at $4^{\circ} \mathrm{C}$ for $\left.10 \mathrm{~min}\right)$ to recover proteins. The protein concentration of samples was measured by a Bradford protein assay. Equal amounts of protein from each sample were separated with sodium dodecylsufate-polyacrylamide gel electrophoresis ( $10 \%$ polyacrylamide) and transferred to a nitrocellulose membrane. Membranes were blocked for $1 \mathrm{~h}$ in $5 \%$ milk/TBS Tween 20 and incubated overnight at $4{ }^{\circ} \mathrm{C}$ with primary antibody in $2.5 \%$ milk/TBST. Following three washes in TBST, secondary antibody (Santa Cruz biotechnology) at a concentration of 1:2000 in 2.5\% milk/TBST was added for $1 \mathrm{~h}$ at room temperature. Antibody binding was visualized with the enhanced chemiluminescence detection system (Thermo Fischer Scientific). Images were captured with a Chemigenius2 system (Syngene, Frederick, MD, USA) and band intensities were calculated with GeneTools software (Syngene).

Antibodies used were as follows: calponin (Abcam, product number ab46794), connexin 43 (Cell Signaling, product number 3512 ) smooth muscle $\alpha$-actin (Santa Cruz Biotechnology, product number sc-32251), $\beta$-actin (Abcam, product number ab6276), MMP2 (Abcam, product number 3158), MMP9 (Abcam, product number ab38898), and TIMP2 (Cell Signaling Technology, product number 5738).

\section{Collagen Gel Contraction Assay}

Twelve-well culture dishes were coated with $1 \%$ bovine serum albumin (BSA) and incubated for $1 \mathrm{~h}$ at $37^{\circ} \mathrm{C}$ to create a nonstick surface that prevents gels from attaching to the dishes. Before performing contraction assays, smooth muscle cells were treated for $72 \mathrm{~h}$ with Wnt3a. Cells were then trypsinized, counted and seeded into a $0.5 \mathrm{mg} / \mathrm{ml}$ Type I collagen solution (BD Biosciences, product number 354236) in growth media at a concentration of $1 \times 10^{5} \mathrm{cells} / \mathrm{ml}$. The collagen/cell suspension was vortexed, and $1 \mathrm{ml}$ per well was added to the BSA-coated dishes and the solution was allowed to polymerize for $45 \mathrm{~min}$ at $37^{\circ} \mathrm{C}$. Fresh growth media was added to the solidified collagen gels and plates were returned to the incubator. Collagen gel contraction was monitored over a period of $48 \mathrm{~h}$ and the surface area of contracted gels was measured using Image-Pro Plus software (Media Cybernetics, Bethesda, MD, USA).

\section{Immunohistochemistry}

Cells were fixed for $20 \mathrm{~min}$ in $3.7 \%$ formaldehyde, permeabilized with $0.1 \%$ triton X-100 for $20 \mathrm{~min}$, blocked for $30 \mathrm{~min}$ with $1 \% \mathrm{BSA}$ in PBS and incubated overnight at $4{ }^{\circ} \mathrm{C}$ with the indicated primary antibody at a concentration of 1:100 in 1\% BSA. Following primary antibody, cells were washed with PBS and incubated with anti-mouse Alexa-fluor conjugated 
secondary antibody (Invitrogen) at a concentration of 1:200 in $1 \%$ BSA for $1 \mathrm{~h}$ at room temperature in the dark. To visualize f-actin, permeabilized cells were stained for $20 \mathrm{~min}$ with phalloidin conjugated to Alexa-fluor594 (Invitrogen). Cells were coverslipped with VectaShield mounting medium containing DAPI (Vector Laboratories) and images were captured using a Leica AOBS SP2 confocal microscope as we have described previously. ${ }^{21,22}$

Antibodies used for staining were as follows: $\beta$-catenin (BD Biosciences, product number 610154) and connexin 43 (Cell Signaling, product number 3512).

\section{Scrape-Loading Dye Transfer Assay}

The gap junction intercellular communication was measured using the scrape-loading dye transfer method, as described previously. ${ }^{23}$ Briefly, cells were cultured on glass coverslips in 6-well dishes until confluent in the presence or absence of Wnt3a. Cells were rinsed twice with PBS, and 0.05\% Lucifer Yellow was then added to the dishes. Scrapes were made through the confluent cultures with a sterile scalpel, and the cells were incubated in the dye mix for precisely $1 \mathrm{~min}$, rinsed quickly three times with PBS, and fixed with formaldehyde. Cells were coverslipped and visualized by confocal microscopy as described above.

\section{Statistical Analysis}

Results are represented as the mean \pm s.d. Significant differences in treatment groups were determined using the unpaired Student's $t$-test. For all analyses, $P<0.05$ was considered statistically significant.

\section{RESULTS \\ Wnt3a Activates Canonical Wnt Signaling in Mouse Vascular Smooth Muscle Cells}

Smooth muscle cells were treated for $24 \mathrm{~h}$ with $250 \mathrm{ng} / \mathrm{ml}$ of Wnt3a (or the vehicle control) and immunohistochemistry for $\beta$-catenin was performed. A clear nuclear accumulation of $\beta$-catenin was observed in the Wnt3a-treated cells (Figure 1a), suggesting Wnt3a activates canonical Wnt signaling. The vehicle-treated cells remained negative for nuclear $\beta$-catenin. To confirm activation of canonical Wnt signaling by Wnt3a, mRNA expression of axin2, an early immediate target of canonical Wnt signaling, was measured after $24 \mathrm{~h}$ of Wnt3a treatment. Wnt3a induced a $71.2 \pm 9.6-$ fold increase in axin2 mRNA expression compared with vehicle-treated control cells (Figure $1 \mathrm{~b}, P<0.05$ ).

\section{Wnt3a Alters the Phenotype of Vascular Smooth Muscle Cells}

Wnt3a induced a marked change in smooth muscle cell phenotype following $72 \mathrm{~h}$ of treatment. The Wnt3a-treated cells appeared larger, flatter, and had increased formation of stress fibers than the vehicle-treated control cells when visualized by actin staining and confocal microscopy (Figure 2a). This change in morphology was associated with significantly decreased proliferation after $72 \mathrm{~h}$ incubation with Wnt3a (Figure $2 \mathrm{~b}$, relative rate $=0.79 \pm 0.13$ of control cells, $P<0.05)$. We next examined this phenotypic change in more detail. The Wnt3a-treated cells demonstrated increased expression of the smooth muscle contractile proteins, calponin and smooth muscle $\alpha$-actin (Figure 3a). Consistent with this, the Wnt3a-treated cells contracted a collagen lattice
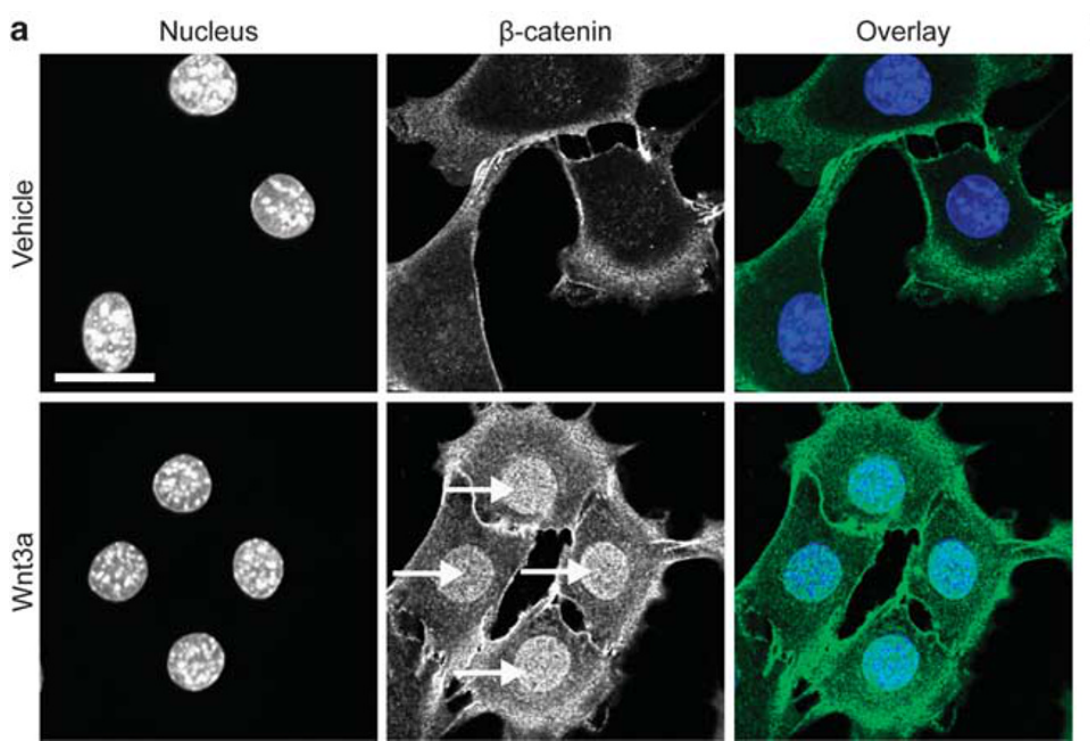

b

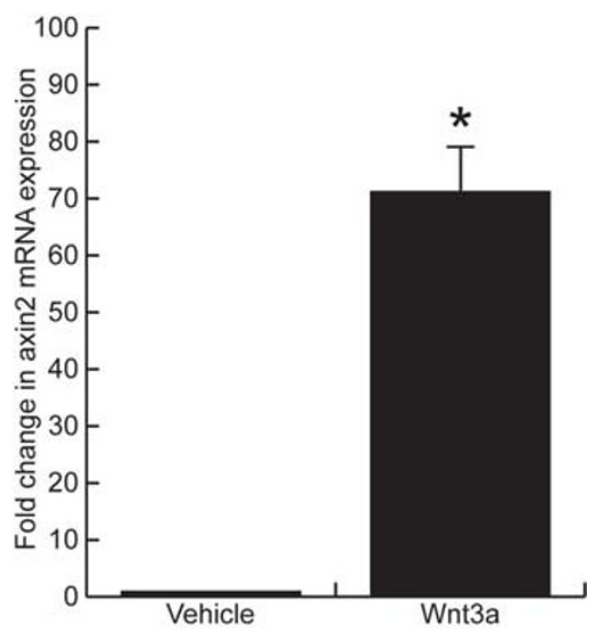

Figure 1 Wnt3a activates canonical Wnt signaling in vascular smooth muscle cells. (a) Smooth muscle cells immunostained for cell nuclei (blue) and $\beta$-catenin (green) showing nuclear accumulation of $\beta$-catenin in the Wnt3a-treated cells (arrows). (b) Wnt3a-treated cells had a 71.2 \pm 9.6 -fold increase in axin2 mRNA expression $(P<0.05)$, an immediate target gene of canonical Wnt signaling. (Scale bar $=23.00 \mu \mathrm{m}$ in panel a, $\left.{ }^{\star} P<0.05\right)$. 

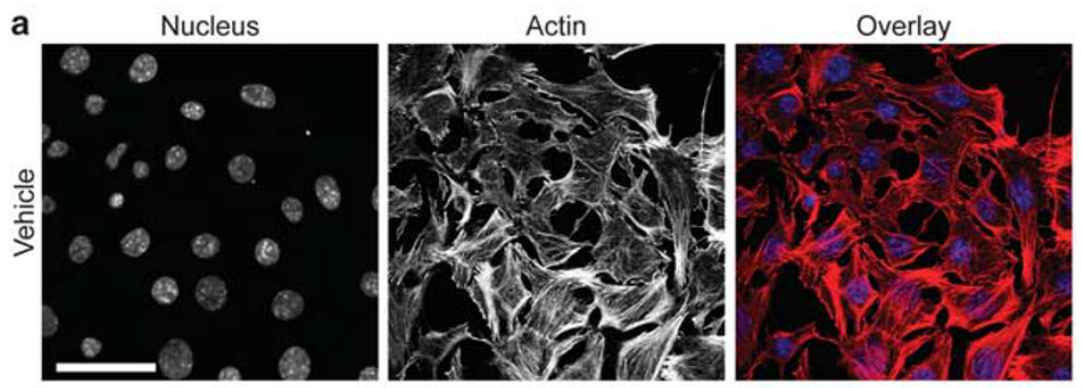

b
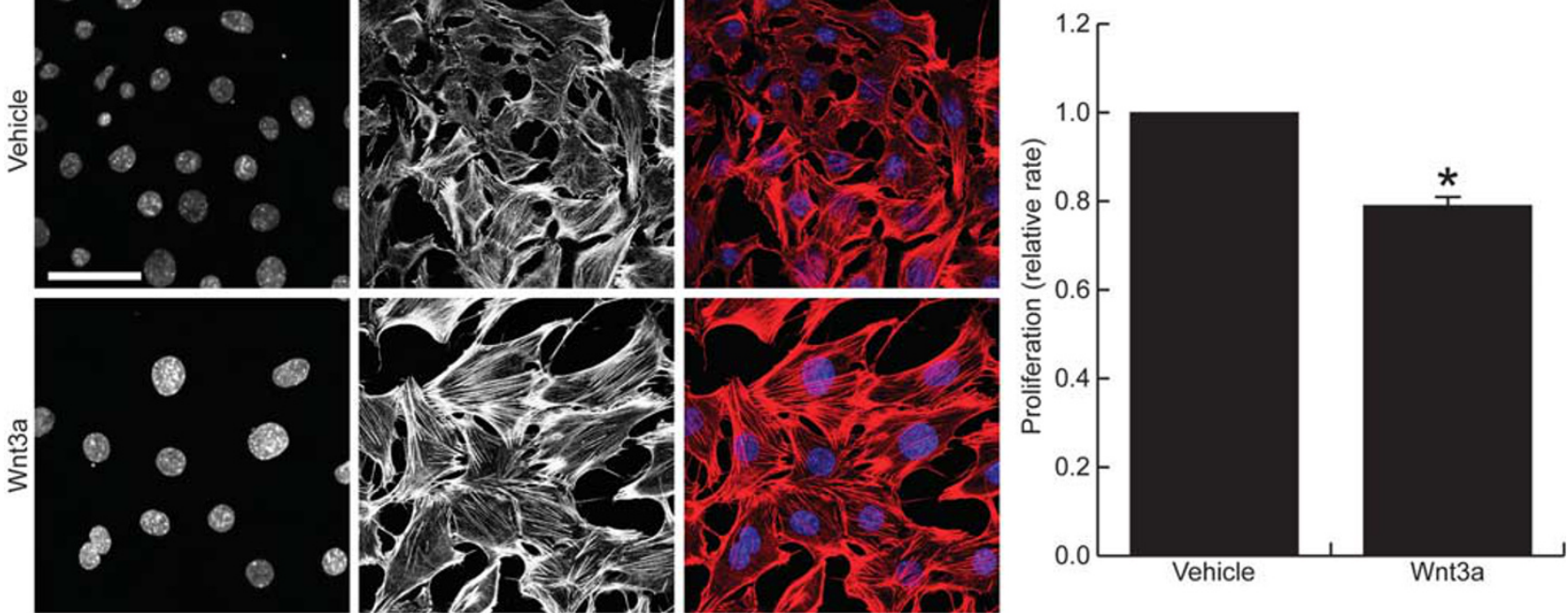

Figure 2 Wnt3a alters the phenotype of vascular smooth muscle cells. (a) Confocal images of smooth muscle cells stained for cell nuclei (blue) and f-actin (red) showing the altered morphology of cells following Wnt3a treatment. The Wnt3a-treated cells appeared larger and acquired a flattened morphology characterized by increased stress fibre formation. (b) Cell proliferation was found to be significantly decreased in Wnt3a-treated cells (relative rate $=0.79 \pm 0.13$ of control cells, $P<0.05$ ). (Scale bar $=46.00 \mu \mathrm{m}$ in panel $\mathbf{a},{ }^{\star} P<0.05$ ).

a

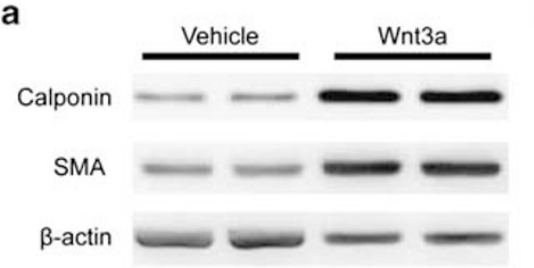

b
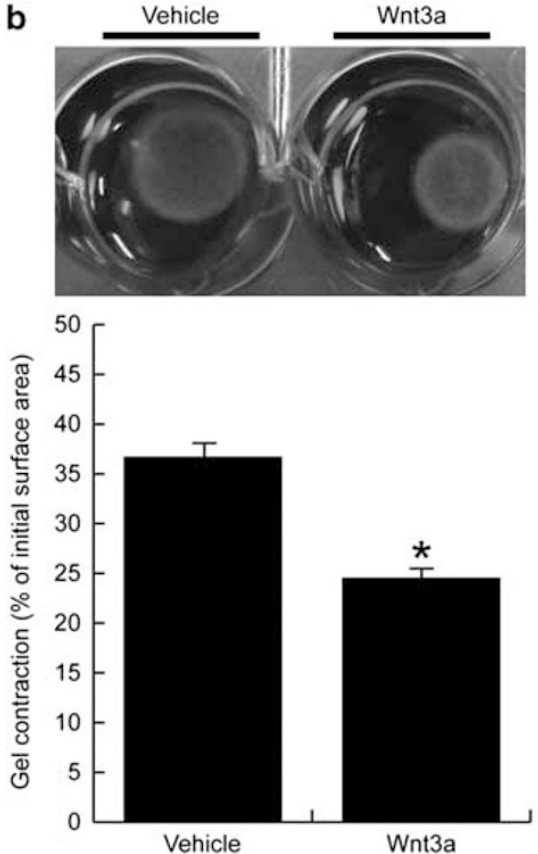

C Wnt3a

$(\mathrm{ng} / \mathrm{mL}) \quad 0 \quad 50 \quad 100 \quad 150 \quad 200 \quad 250 \quad 300$

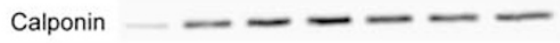

$\mathrm{SMA}=-\infty-$

$\beta$-actin - - - - -

d

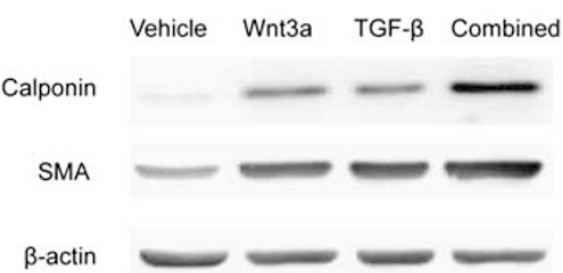

Figure $3 \mathrm{Wnt} 3 \mathrm{a}$ increases contractile properties of vascular smooth muscle cells. (a) Representative western blot images showing the increased expression of calponin and smooth muscle $\alpha$-actin in Wnt3a-treated cells. (b) Wnt3a increased cell-mediated contraction of a collagen lattice, after a 72 -h treatment $24.5 \pm 0.8 \%$ vs $36.7 \pm 0.9 \%$ of initial gel area, $P<0.05$ ). (c) Dose response shows Wnt3a increased calponin and smooth muscle $\alpha$-actin at all concentrations tested.

(d) Combined treatment of Wnt3a and TGF- $\beta$ increased calponin and smooth muscle $\alpha$-actin expression more than either treatment alone. $\left({ }^{\star} P<0.05\right)$. 

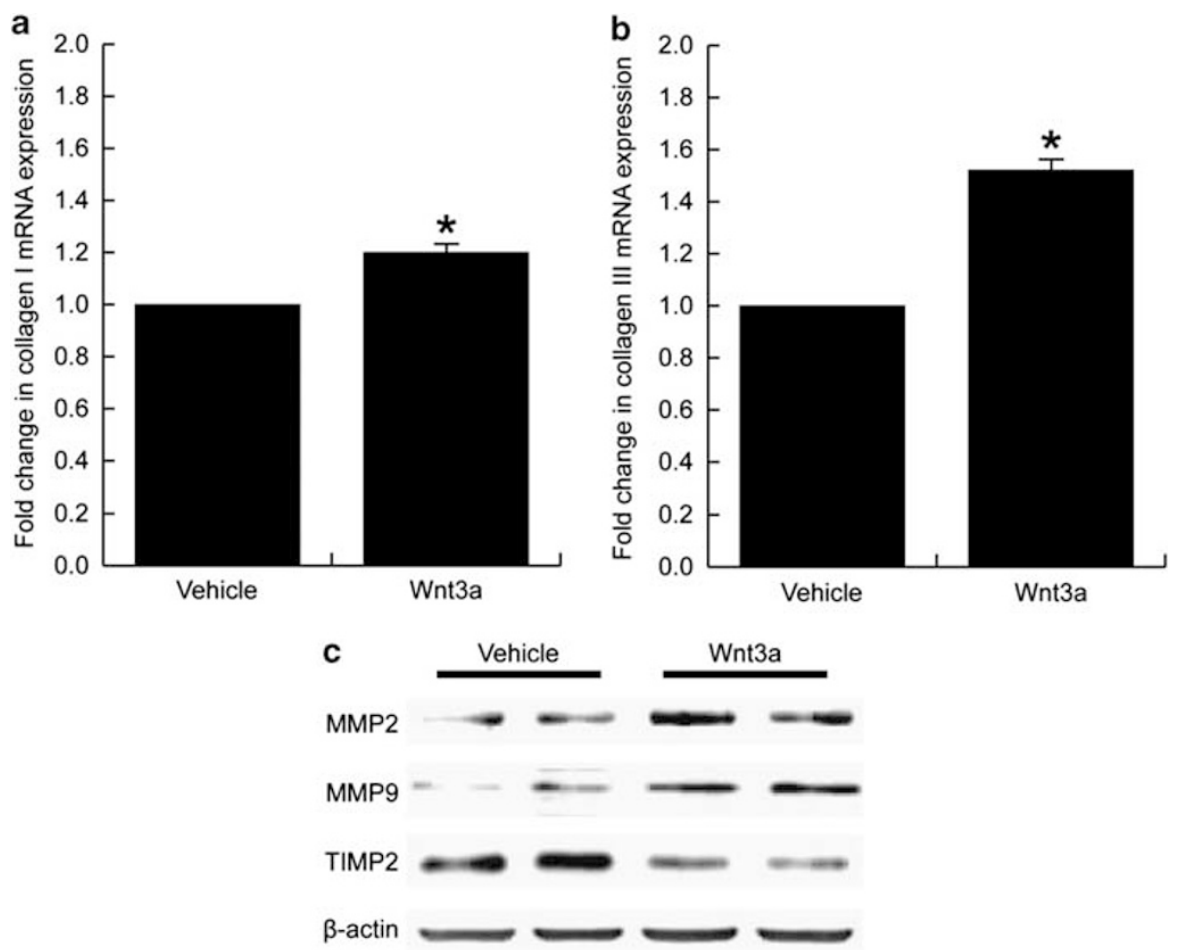

Figure 4 Wnt3a inceases collagen synthesis and protease expression in smooth muscle cells. (a) Wnt3a significantly increased the expression of collagen I mRNA (1.20 \pm 0.04 -fold increase, $P<0.05)$, as well as (b) collagen III mRNA (1.50 \pm 0.04 -fold increase, $P<0.05)$. (c) Representative western blot images showing the increased expression of MMP2 and MMP9, but decreased expression of TIMP2, in Wnt3a-treated cells. $\left({ }^{*} P<0.05\right)$.

significantly faster than control cells, following a 72-h treatment (Figure $3 \mathrm{~b}, 24.5 \pm 0.8 \%$ vs $36.7 \pm 0.9 \%$ of initial gel area, $P<0.05)$. To determine if there was a dose response to Wnt3a, we tested the expression of contractile proteins following treatment over a range of Wnt3a concentrations $(0-300 \mathrm{ng} / \mathrm{ml})$. Wnt3a induced a marked increase in the calponin and smooth muscle $\alpha$-actin expression at all concentrations tested (Figure $3 \mathrm{c}$ ). As growing evidence suggests cross-talk between Wnt signaling and TGF- $\beta$ signaling, ${ }^{24,25}$ we next examined the effect of a combined treatment of Wnt $3 a$ and TGF- $\beta$ on the expression of these proteins. Our data suggest that, while Wnt3a and TGF- $\beta$ both increased the expression of calponin and smooth muscle $\alpha$-actin individually, the combination of these growth factors increased the expression of these proteins even further and in a dramatic fashion (Figure $3 \mathrm{~d}$ ).

Concomitant with the increased contractile protein expression, extracellular matrix synthesis was also increased in Wnt3a-treated fibroblasts, as measured by collagen I and III mRNA expression. The Wnt3a-treated cells had $1.20 \pm 0.04$-fold increase in collagen I mRNA expression and a $1.50 \pm 0.04$-fold increase in collagen III mRNA expression, when compared with the vehicle-treated control cells (Figures $4 \mathrm{a}$ and $\mathrm{b}$, respectively, $P<0.05)$. These cells also displayed increased expression of MMP2 and MMP9, but decreased TIMP2 levels (Figure 4c), suggesting Wnt3a induced a shift in balance in these matrix proteases and their inhibitors.

\section{Wnt3a Increases Connexin 43 Expression and Intercellular Communication in Smooth Muscle Cells}

We next examined the expression of connexin 43, a gap junction protein and the principal connexin expressed in arterial smooth muscle cells. ${ }^{26-28}$ The Wnt3a-treated smooth muscle cells displayed increased connexin 43 expression, as measured by western blot (Figure 5a). Densitometry showed Wnt3a increased connexin 43 expression $1.71 \pm 0.09$-fold when compared with control cells (Figure 5b, $P<0.05$ ). Immunohistochemistry confirmed the increased connexin 43 expression seen in the Wnt3a-treated cells, and showed the connexin 43 to localize at cell-cell junctions between neighboring cells (Figure $5 \mathrm{c}$ ). To determine if the increased connexin 43 expression in Wnt3a-treated cells correlated with increased intercellular communication, we performed a scrape-loading dye transfer assay. Representative images of dye transfer are shown in Figure 6a. Quantification showed the relative distance of dye transfer to be significantly increased in Wnt3a-treated cells (Figure 6b, relative distance $=0.86 \pm 0.09$ in Wnt3a cells $v s 0.16 \pm 0.03$ in control cells, $P<0.05, N=9$ for each treatment group).

\section{Wnt3a-Induced Change in Smooth Muscle Cell Phenotype is Dependent on Canonical Wnt Signaling}

To determine if the altered cell phenotype induced by Wnt3a is dependent on canonical Wnt signaling, DKK1 was added during Wnt3a treatment. Incubation with DKK1 eliminated 
a

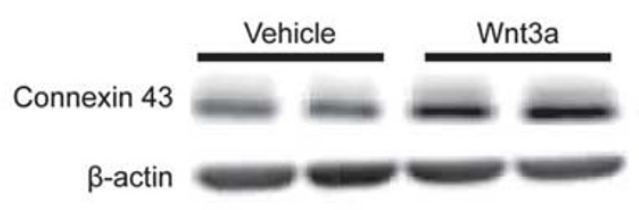

C
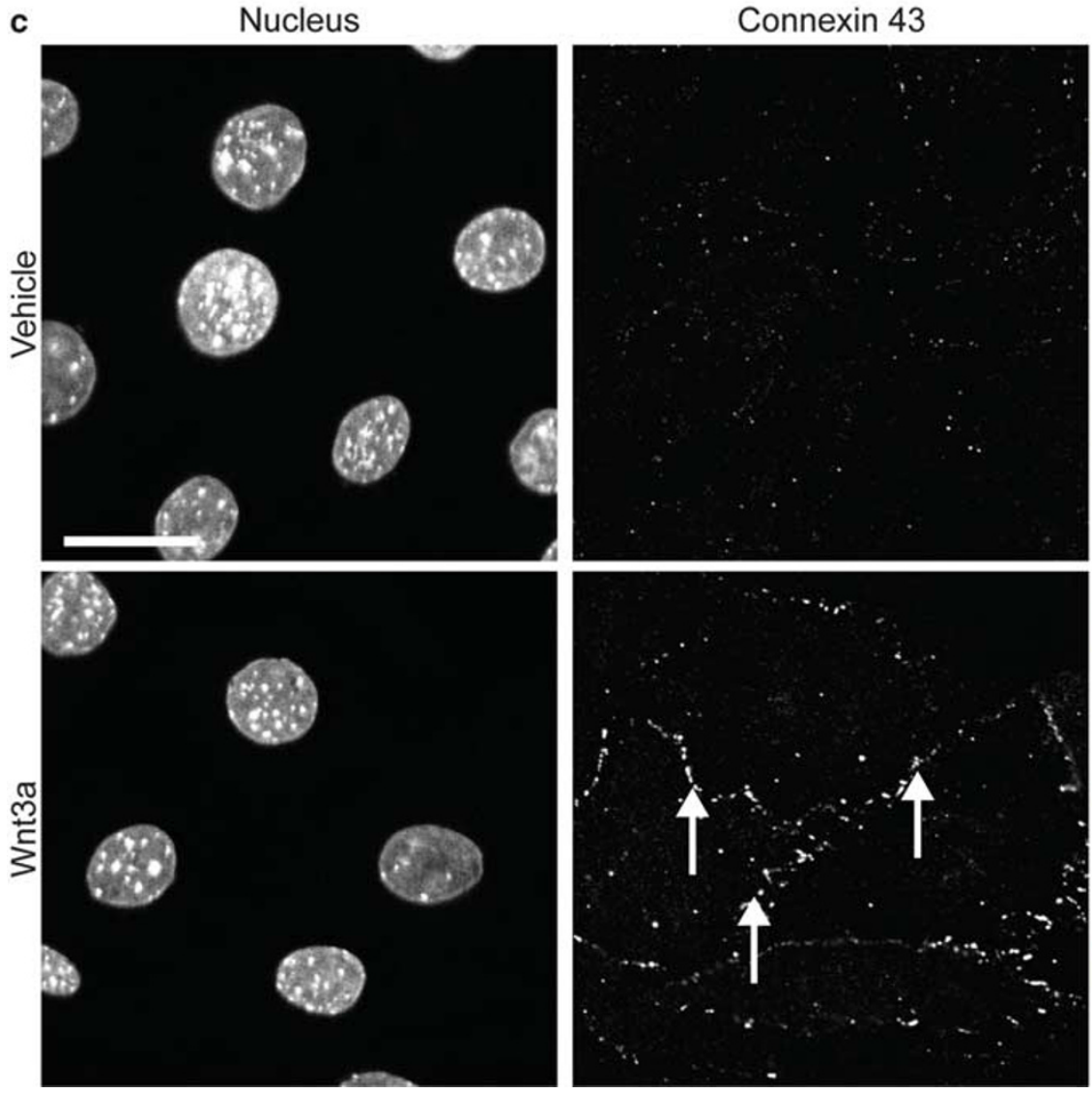

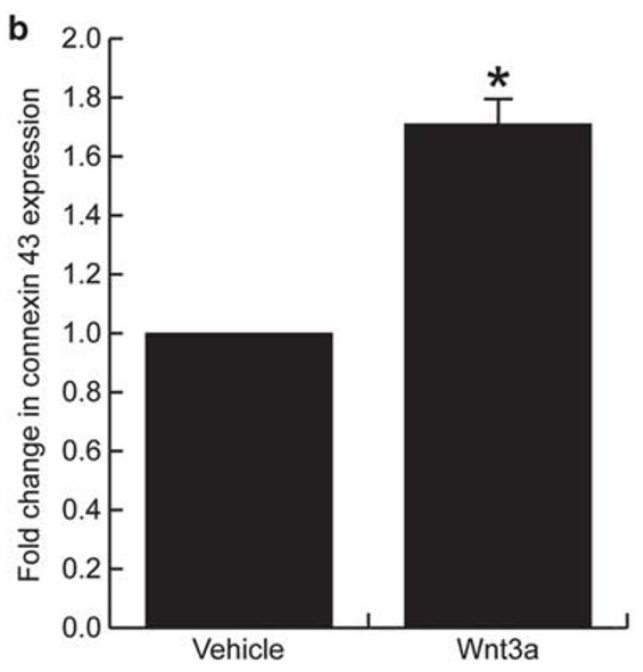

Connexin 43
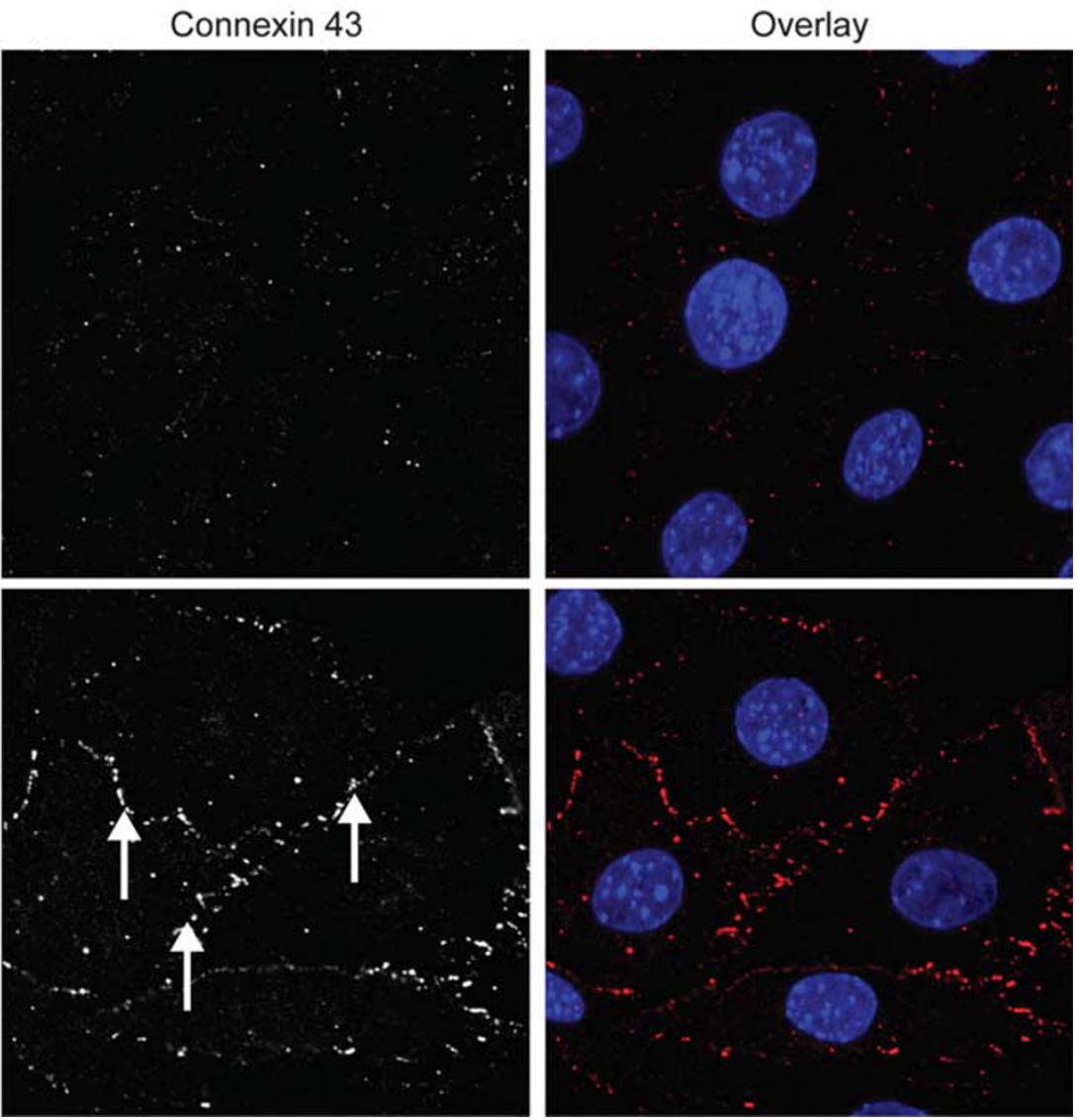

Figure 5 Wnt3a increases connexin 43 expression in smooth muscle cells. (a) Representative western blot showing the increased connexin 43 expression in Wnt3a-treated smooth muscle cells. (b) Densitometry showed the change in connexin 43 expression to be significant $(1.71 \pm 0.09$-fold increase, $P<0.05)$. (c) Confocal images of cells immunostained for cell nuclei (blue) and connexin 43 (red) showing the increased expression and localization of connexin 43 at cell-cell junctions (arrows). (Scale bar $=23.00 \mu \mathrm{m}$ in panel $\mathbf{c}$, ${ }^{\star} P<0.05$ ).

the Wnt3a-induced expression of axin2 mRNA at $24 \mathrm{~h}$, confirming it effectively antagonized canonical Wnt signaling (Figure 7a, fold change in axin 2 mRNA expression, compared with vehicle-treated control cells, was $1.07 \pm 0.97$ for DKK1 alone, $421.21 \pm 136.39$ for Wnt3a alone, and $10.18 \pm 11.69$ for the combined Wnt3a and DKK1 treatment). Following a 72-h incubation with Wnt3a, DKK1 completely inhibited the Wnt3a-induced expression of calponin and smooth muscle $\alpha$-actin, as demonstrated by western blot (Figure $7 \mathrm{~b}$ ). Further, the increased expression of connexin 43 that was seen in Wnt3a-treated cells was completely eliminated in the presence of DKK1, as demonstrated by immunohistochemistry 
and confocal microscopy (Figure 7c), indicating the Wnt3a-induced change in cell phenotype was dependent on canonical Wnt signaling.

\section{DISCUSSION}

In this study, we have shown that Wnt3a alters the phenotype of vascular smooth muscle cells. Structurally, Wnt3a induced a larger morphology in smooth muscle cells that was characterized by increased stress fibre formation. These cells displayed upregulated expression of the smooth muscle contractile proteins, calponin and smooth muscle $\alpha$-actin, along with increased expression of the extracellular matrix genes collagen I and III, and an altered balance in the expression of matrix proteases and their inhibitors. Functionally, the Wnt3a-treated cells proliferated slower than control cells but contracted a collagen lattice faster. Collectively, this data suggest Wnt3a induced a contractile and synthetic phenotype in vascular smooth muscle cells. This change in cell phenotype induced by Wnt3a was associated with an increase in expression of the gap junction protein connexin 43 and increased cell-cell communication.
These changes appeared to occur via canonical Wnt signaling, as DKK1 blocked the Wnt3a-mediated change in cell phenotype. Altogether, this data suggest Wnt3a alters the phenotype of vascular smooth muscle cells. As Wnt signaling is upregulated after vascular injury, ${ }^{7,14}$ this data highlight a potential role for Wnt3a in controlling smooth muscle cell phenotype during vascular wound repair and remodeling processes.

Our work is consistent with previous reports that have suggested a role for Wnt signaling in modifying cell phenotype and fate. ${ }^{20,29,30}$ Our data suggest Wnt3a induced a smooth muscle cell phenotype with increased expression of contractile proteins as well as increased expression of extracellular matrix genes. Thus, it appears Wnt3a simultaneously induced a contractile and synthetic phenotype in smooth muscle cells. Normally, vascular smooth muscle cells form the medial layer of blood vessels where they are found in a differentiated contractile phenotype. ${ }^{31}$ However, numerous vascular diseases are characterized by the accumulation of smooth muscle cells in the intimal layer of blood vessels where they are surrounded by newly synthesized extracellular
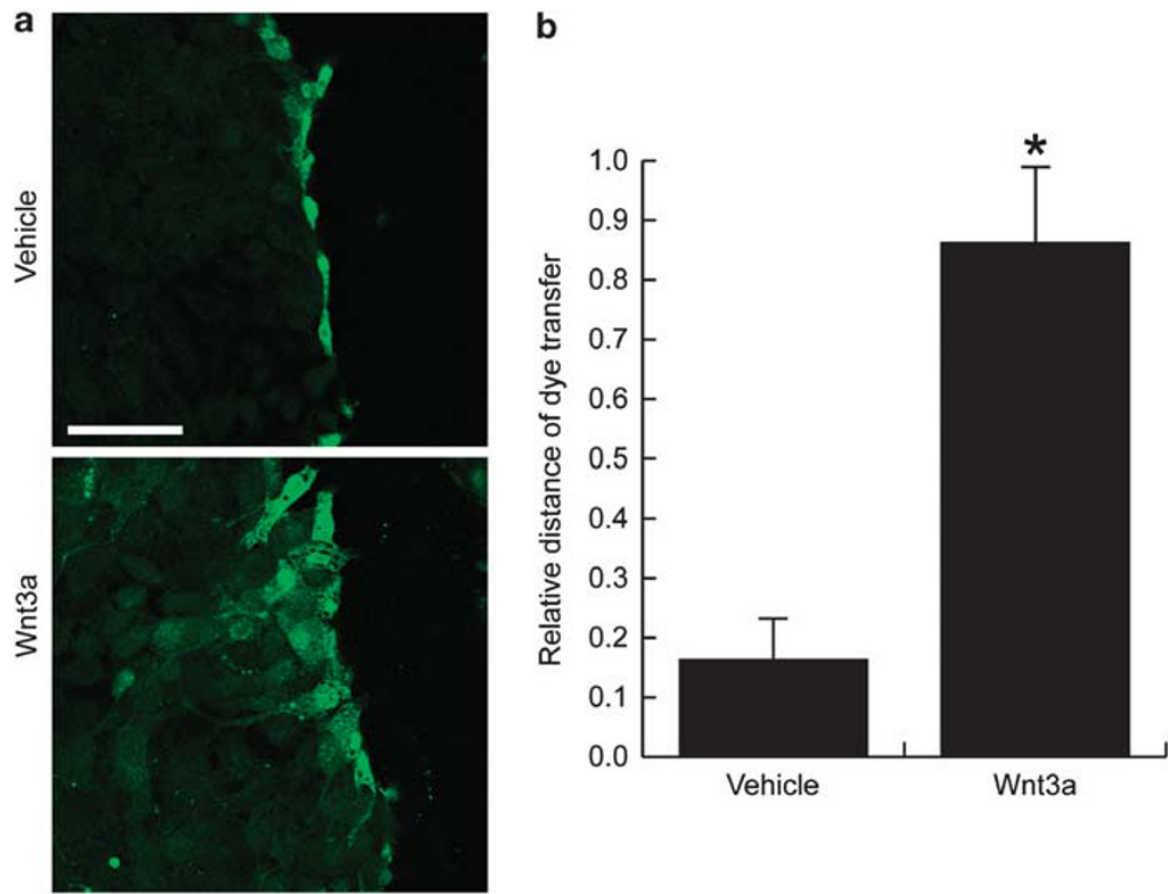

Figure 6 Wnt3a increases gap junction communication in vascular smooth muscle cells. (a) Representative images showing the increased transfer of lucifer yellow in Wnt3a-treated cells, as measured by scrape-loading dye transfer. (b) Quantification showed the relative distance of dye transfer to be significantly increased in Wnt3a-treated cells (relative distance $=0.86 \pm 0.09$ in Wnt3a cells vs $0.16 \pm 0.03$ in control cells, $P<0.05) .\left({ }^{*} P<0.05\right)$.

Figure 7 Wnt3a-mediated change in smooth muscle cell phenotype and connexin 43 expression is dependent on canonical Wnt signaling. (a) Treatment of smooth muscle cells with DKK1 significantly decreased the Wnt3a-induced axin2 mRNA expression (fold change in mRNA expression, compared with vehicle-treated cells, was $1.07 \pm 0.97$ for DKK1, $421.21 \pm 136.39$ for Wnt3a, and 10.18 \pm 11.69 for the combined Wnt3a and DKK1 treatment).

(b) Representative western blots show DKK1 decreased the Wnt3a-induced calponin and smooth muscle $\alpha$-actin expression. (c) Confocal images of smooth muscle cells stained for cell nuclei (blue) and connexin 43 (red) show the increased expression of connexin 43 in Wnt3a-treated cells (arrows) is eliminated in the presence of DKK1. (Scale bar $=23.00 \mu \mathrm{m}$ in panel $\mathbf{c},{ }^{\star} P<0.05$ ). 


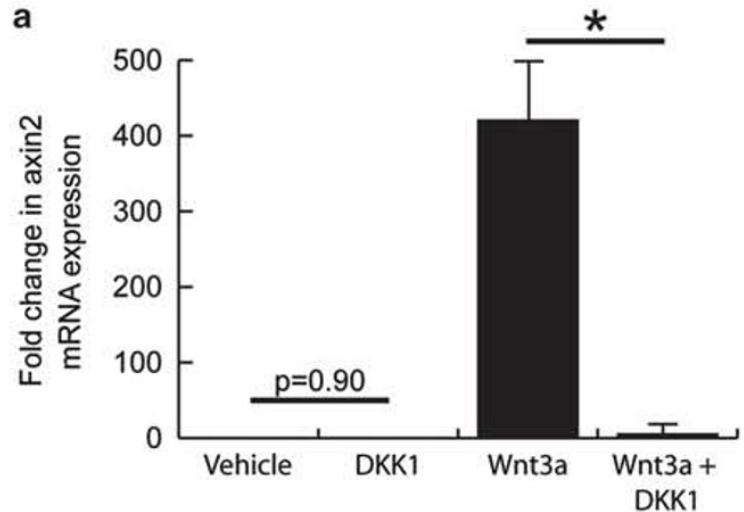

b

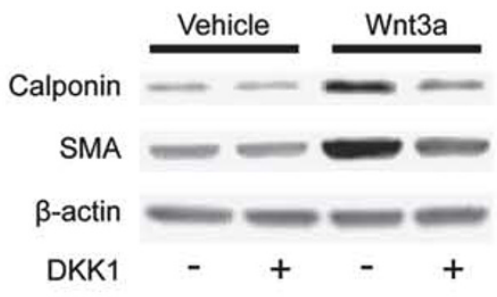

C

Vehicle

Wnt3a
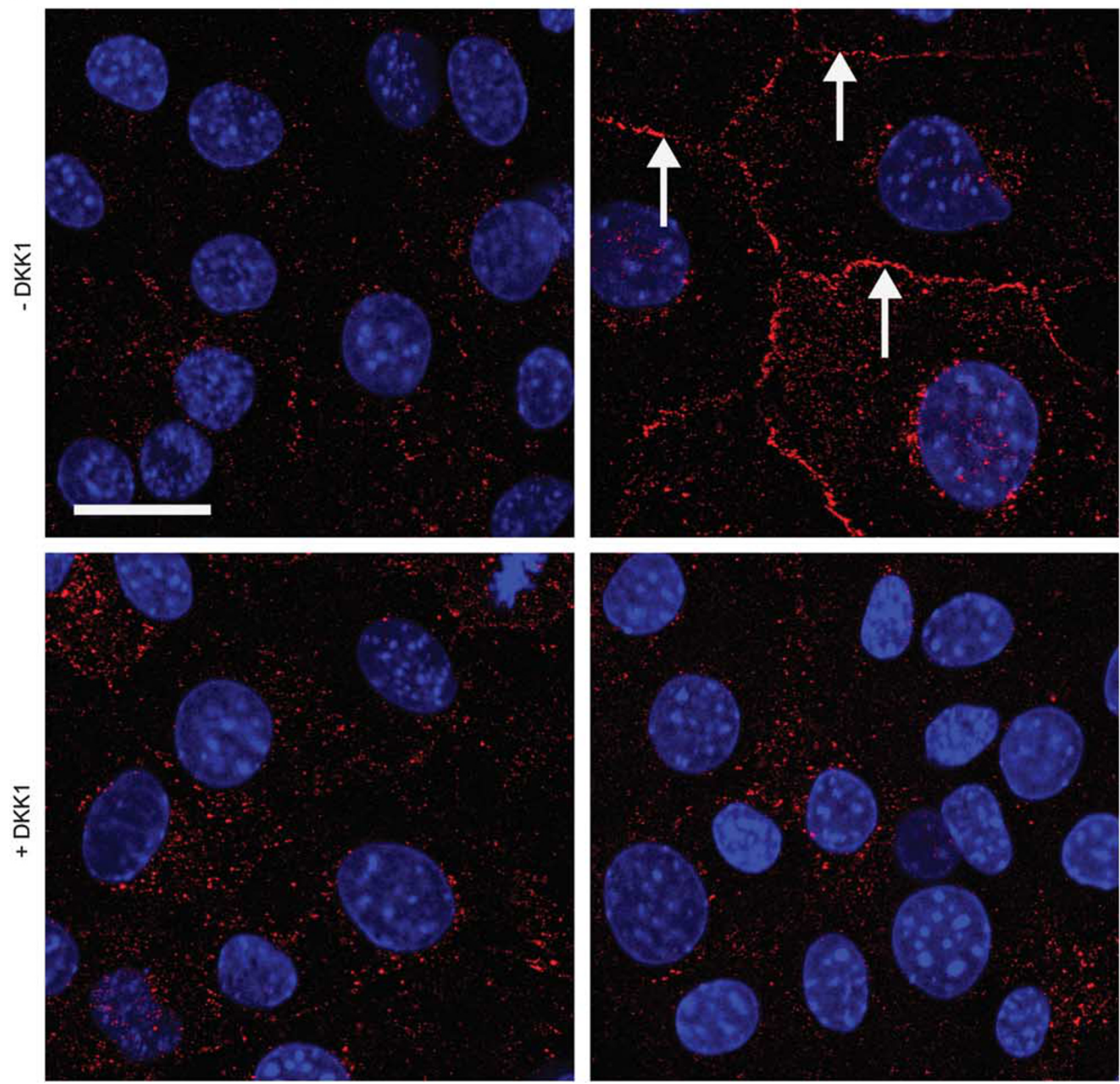
matrix. ${ }^{3,4,32}$ These cells are generally thought of as dedifferentiated and synthetic, in that they display a loss of contractile differentiation, but an increased capacity to synthesize matrix proteins. ${ }^{31}$ Although traditionally it has been thought that smooth muscle cells existed in either a synthetic or contractile state, it is now being recognized that there is considerable heterogeneity in smooth muscle cell populations and in some instances, contractile differentiation markers may be expressed simultaneously with matrix synthesis. ${ }^{3-35}$ Our data are in support of this idea that contractile differentiation and increased matrix synthesis are not mutually exclusive in vascular smooth muscle cells. In fact, these cells appear to resemble a myofibroblast-like cell type in nature, which is a specialized wound repair fibroblast characterized by increased contractile ability and matrix synthesis. ${ }^{36}$ Our previous work has suggested that Wnt3a induces myofibroblast differentiation in murine fibroblasts, ${ }^{20}$ and it is tempting to speculate that a similar process may be occurring in vascular smooth muscle cells. More work will be needed to determine whether this relationship between Wnt signaling and smooth muscle cell phenotype exists in vivo, and how such a cell phenotype modifies vascular development and disease.

Gap junctions are clusters of transmembrane channels, which directly link adjacent cells and allow for the passage of ions and small signaling molecules. ${ }^{37}$ Thus, gap junctions allow cells to coordinate their functions. These channels are comprised of subunit proteins encoded by the multigene connexin family, of which connexin 43 is the predominant connexin expressed by vascular smooth muscle cells. ${ }^{28}$ It has previously been reported that connexin 43 expression is upregulated in smooth muscle cells in response to injury in rodent models and in early human atherosclerosis, situations in which elevated Wnt signaling has been reported ${ }^{7,14}$ and in which increased extracellular matrix synthesis is well documented. ${ }^{3,38}$ Reducing connexin 43 expression has been shown to inhibit lesion development in rodent models of atherosclerosis and acute vascular injury, ${ }^{39-41}$ suggesting potential pro-atherogenic functions for gap junction communication. Our data suggest Wnt3a increases the expression of connexin 43 in vascular smooth muscle cells, and this increase in connexin 43 expression is associated with increased intercellular communication and matrix synthesis. A recent report has demonstrated that TGF- $\beta$ also induced a contractile and synthetic phenotype in vascular smooth muscle cells, which correlated with increased connexin 43 expression and intercellular communication. ${ }^{35}$ When taken together, these studies imply a role for connexin 43 in the Wnt3a- and TGF- $\beta$-mediated smooth muscle cell differentiation and matrix synthesis. In support of this idea, recent studies have highlighted a potential role for connexin 43 hemichannels in regulating vascular smooth muscle cell phenotype in response to balloon injury and other mitogenic stimuli. ${ }^{41,42}$ Further, our data suggest that the presence of both Wnt3a and TGF- $\beta$ may have an additive effect on cell phenotype, as we observed their combined effects to be much greater than the effect of either protein individually.

Wnt proteins are believed to signal through three distinct pathways, of which the classical or canonical Wnt/ $\beta$-catenin cascade is the best understood. The other pathways include the noncanonical planar cell polarity pathway and the Wnt/Ca ${ }^{2+}$ pathway. ${ }^{16}$ By using DKK1, we were able to demonstrate that blocking canonical Wnt signaling reversed the Wnt3a-induced change in cell phenotype, suggesting these changes were mediated through the classical Wnt signaling pathway. There is sufficient evidence to suggest a role for canonical Wnt signaling in the development of atheromatous vascular disease. ${ }^{13} \mathrm{~A}$ link between $\beta$-catenin stabilization and smooth muscle cell proliferation has been demonstrated both in vitro and after balloon catheter injury. ${ }^{7,10,43}$ Oxidized LDL has also been shown to stimulate smooth muscle cell migration in a mechanism that was dependent on $\beta$-catenin signaling. ${ }^{44}$ A number of confirmed Wnt target genes, including versican, ${ }^{19}$ fibronectin ${ }^{45}$ and matrix metalloproteases, ${ }^{46}$ are upregulated after vascular injury and appear to promote inflammation and atheroma formation. ${ }^{47-49}$ Our data add to this story by suggesting canonical Wnt signaling promotes a contractile and secretory phenotype in vascular smooth muscle cells. We also observed an alteration to the balance of protease expression, as both MMP2 and MMP9 expression were increased while the protease inhibitor TIMP2 was decreased, signifying Wnt3a may stimulate an active remodeling process in smooth muscle cells. Although a link between Wnt signaling and vascular calcification has been established, ${ }^{50}$ to our knowledge, there are no functional studies that have assessed the impact of inhibiting Wnt signaling in experimental models of vascular wound repair and disease. Clearly this is an area that should be explored in the future.

In summary, we provide data on a novel role for Wnt3a in altering the phenotype of cultured vascular smooth muscle cells. Our data suggest Wnt3a promotes a contractile and secretory phenotype in smooth muscle cells that is associated with the increased expression of connexin 43 . These changes appear to be mediated by canonical Wnt signaling. As smooth muscle cells are critically involved in normal and aberrant vascular injury and repair events, this data suggest a potential role for Wnt3a in regulating vascular wound repair and remodeling events.

\section{ACKNOWLEDGEMENTS \\ This work was supported by a grant-in-aid from the Heart and Stroke Foundation of British Columbia and Yukon.}

\section{DISCLOSURE/CONFLICT OF INTEREST}

The authors declare no conflict of interest.

1. Garratt KN, Edwards WD, Kaufmann UP, et al. Differential histopathology of primary atherosclerotic and restenotic lesions in coronary arteries and saphenous vein bypass grafts: analysis 
of tissue obtained from 73 patients by directional atherectomy. J Am Coll Cardiol 1991;17:442-448.

2. Schwartz RS, Holmes Jr DR, Topol EJ. The restenosis paradigm revisited: an alternative proposal for cellular mechanisms. J Am Coll Cardiol 1992;20:1284-1293.

3. Farb A, Kolodgie FD, Hwang JY, et al. Extracellular matrix changes in stented human coronary arteries. Circulation 2004;110:940-947.

4. Geary RL, Nikkari ST, Wagner WD. et al. Wound healing: a paradigm for lumen narrowing after arterial reconstruction. J Vas Surg 1998;27: 96-106; discussion 106-108.

5. Barrientos S, Stojadinovic O, Golinko MS, et al. Growth factors and cytokines in wound healing. Wound Repair Regen 2008;16:585-601.

6. Lusis AJ. Atherosclerosis. Nature 2000;407:233-241.

7. Wang $X$, Xiao $Y$, Mou $Y$, et al. A role for the beta-catenin/T-cell factor signaling cascade in vascular remodeling. Circ Res 2002;90:340-347.

8. Uglow EB, Slater S, Sala-Newby GB, et al. Dismantling of cadherinmediated cell-cell contacts modulates smooth muscle cell proliferation. Circ Res 2003;92:1314-1321.

9. Dwivedi A, Slater SC, George SJ. MMP-9 and -12 cause N-cadherin shedding and thereby beta-catenin signalling and vascular smooth muscle cell proliferation. Cardiovasc Res 2009;81:178-186.

10. Quasnichka H, Slater SC, Beeching CA, et al. Regulation of smooth muscle cell proliferation by beta-catenin/T-cell factor signaling involves modulation of cyclin D1 and p21 expression. Circ Res 2006:99:1329-1337.

11. Christman 2nd MA, Goetz DJ, Dickerson E, et al. Wnt5a is expressed in murine and human atherosclerotic lesions. Am J Physiol Heart Circ Physiol 2008;294:H2864-H2870.

12. Tsaousi $A$, Williams $H$, Lyon $C A$, et al. Wnt4/beta-catenin signaling induces VSMC proliferation and is associated with intimal thickening Circ Res 2011;108:427-436.

13. Lyon C, Mill C, Tsaousi A, et al. Regulation of VSMC behavior by the cadherin-catenin complex. Front Biosci 2011;16:644-657.

14. Gosens $R$, Meurs $H$, Schmidt M. The GSK-3/beta-catenin-signalling axis in smooth muscle and its relationship with remodelling. Naunyn-Schmiedeberg's Arch Pharmacol 2008;378:185-191.

15. Logan $\mathrm{CY}$, Nusse R. The Wnt signaling pathway in development and disease. Annu Rev Cell Dev Biol 2004;20:781-810.

16. Clevers $\mathrm{H}$. Wnt/beta-catenin signaling in development and disease. Cell 2006;127:469-480.

17. Brade T, Manner J, Kuhl M. The role of Wnt signalling in cardiac development and tissue remodelling in the mature heart. Cardiovasc Res 2006;72:198-209.

18. Nelson WJ, Nusse R. Convergence of Wnt, beta-catenin, and cadherin pathways. Science 2004;303:1483-1487.

19. Rahmani M, Read JT, Carthy JM, et al. Regulation of the versican promoter by the beta-catenin-T-cell factor complex in vascular smooth muscle cells. J Biol Chem 2005;280:13019-13028.

20. Carthy JM, Garmaroudi FS, Luo Z, et al. Wnt3a induces myofibroblast differentiation by upregulating TGF-beta signaling through SMAD2 in a beta-catenin-dependent manner. PLoS One 2011;6:e19809.

21. Marchant D, Sall A, Si X, et al. ERK MAP kinase-activated Arf6 trafficking directs coxsackievirus type B3 into an unproductive compartment during virus host-cell entry. J Gen Virol 2009;90(Pt 4):854-862.

22. Rezai N, Corbel SY, Dabiri D, et al. Bone marrow-derived recipient cells in murine transplanted hearts: potential roles and the effect of immunosuppression. Lab Invest 2005;85:982-991.

23. el-Fouly MH, Trosko JE, Chang CC. Scrape-loading and dye transfer. A rapid and simple technique to study gap junctional intercellular communication. Exp Cell Res 1987;168:422-430.

24. Shafer SL, Towler DA. Transcriptional regulation of SM22alpha by Wnt3a: convergence with TGFbeta/Smad signaling at a novel regulatory element. J Mol Cell Cardiol 2009:46:621-635.

25. Natsume $H$, Tokuda $H$, Matsushima-Nishiwaki R, et al. Wnt3a upregulates transforming growth factor-beta-stimulated VEGF synthesis in osteoblasts. Cell Biochem Funct 2001;29:371-377.

26. Ko YS, Coppen SR, Dupont E, et al. Regional differentiation of desmin connexin43, and connexin45 expression patterns in rat aortic smooth muscle. Arterioscl Thromb Vasc Biol 2001;21:355-364.

27. Yeh $\mathrm{HI}$, Lupu $\mathrm{F}$, Dupont $\mathrm{E}$, et al. Upregulation of connexin43 gap junctions between smooth muscle cells after balloon catheter injury in the rat carotid artery. Arterioscler Thromb Vas Biol 1997;17:3174-3184.
28. Haefliger JA, Nicod P, Meda P. Contribution of connexins to the function of the vascular wall. Cardiovasc Res 2004;62:345-356.

29. Nalesso G, Sherwood J, Bertrand J, et al. WNT-3A modulates articular chondrocyte phenotype by activating both canonical and noncanonical pathways. J Cell Biol 2011;193:551-564.

30. Carre AL, James AW, MacLeod L, et al. Interaction of wingless protein (Wnt), transforming growth factor-beta1, and hyaluronan production in fetal and postnatal fibroblasts. Plast Reconstr Surg 2010;125: 74-88.

31. Ross R. Cell biology of atherosclerosis. Annu Rev Physiol 1995;57: 791-804.

32. Lin $\mathrm{H}$, Wilson $\mathrm{JE}$, Roberts $\mathrm{CR}$, et al. Biglycan, decorin, and versican protein expression patterns in coronary arteriopathy of human cardiac allograft: distinctness as compared to native atherosclerosis. J Heart Lung Transplant 1996;15:1233-1247.

33. Hao H, Gabbiani G, Bochaton-Piallat ML. Arterial smooth muscle cell heterogeneity: implications for atherosclerosis and restenosis development. Arterioscler Thromb Vasc Biol 2003:23:1510-1520.

34. Matsushita T, Rama A, Charolidi N, et al. Relationship of connexin43 expression to phenotypic modulation in cultured human aortic smooth muscle cells. Eur J Cell Biol 2007;86:617-628.

35. Rama A, Matsushita T, Charolidi N, et al. Up-regulation of connexin43 correlates with increased synthetic activity and enhanced contractile differentiation in TGF-beta-treated human aortic smooth muscle cells. Eur J Cell Biol 2006;85:375-386.

36. Hinz B, Phan SH, Thannickal VJ, et al. The myofibroblast: one function, multiple origins. Am J Pathol 2007:170:1807-1816.

37. Saez JC, Berthoud VM, Branes MC, et al. Plasma membrane channels formed by connexins: their regulation and functions. Physiol Rev 2003;83:1359-1400.

38. Chung IM, Gold HK, Schwartz SM, et al. Enhanced extracellular matrix accumulation in restenosis of coronary arteries after stent deployment. J Am Coll Cardiol 2002;40:2072-2081.

39. Kwak BR, Veillard N, Pelli G, et al. Reduced connexin43 expression inhibits atherosclerotic lesion formation in low-density lipoprotein receptor-deficient mice. Circulation 2003;107:1033-1039.

40. Chadjichristos CE, Matter CM, Roth I, et al. Reduced connexin43 expression limits neointima formation after balloon distension injury in hypercholesterolemic mice. Circulation 2006;113:2835-2843.

41. Song M, Yu X, Cui X, et al. Blockade of connexin 43 hemichannels reduces neointima formation after vascular injury by inhibiting proliferation and phenotypic modulation of smooth muscle cells. Exp Biol Med (Maywood) 2009;234:1192-1200

42. Chadjichristos $C E$, Morel S, Derouette JP, et al. Targeting connexin 43 prevents platelet-derived growth factor-BB-induced phenotypic change in porcine coronary artery smooth muscle cells. Circ Res 2008; 102:653-660.

43. Slater SC, Koutsouki $\mathrm{E}$, Jackson $\mathrm{CL}$, et al. R-cadherin:beta-catenin complex and its association with vascular smooth muscle cell proliferation. Arterioscler Thromb Vasc Biol 2004;24:1204-1210.

44. Bedel A, Negre-Salvayre A, Heeneman S, et al. E-cadherin/beta-catenin/ T-cell factor pathway is involved in smooth muscle cell proliferation elicited by oxidized low-density lipoprotein. Circ Res 2008;103: 694-701.

45. Gradl D, Kuhl M, Wedlich D. The Wnt/Wg signal transduce beta-catenin controls fibronectin expression. Mol Cell Biol 1999; 19:5576-5587.

46. Wu B, Crampton SP, Hughes CC. Wnt signaling induces matrix metalloproteinase expression and regulates $\mathrm{T}$ cell transmigration. Immunity 2007;26:227-239.

47. Goodwin AM, D'Amore PA. Wnt signaling in the vasculature Angiogenesis 2002;5:1-9.

48. Kim S, Takahashi $\mathrm{H}$, Lin WW, et al. Carcinoma-produced factors activate myeloid cells through TLR2 to stimulate metastasis. Nature 2009;457:102-106.

49. Seidelmann SB, Kuo $C$, Pleskac $N$, et al. Athsq1 is an atherosclerosis modifier locus with dramatic effects on lesion area and prominent accumulation of versican. Arterioscler Thromb Vasc Biol 2008;28: 2180-2186.

50. Shao JS, Cheng SL, Pingsterhaus JM, et al. Msx2 promotes cardiovascular calcification by activating paracrine Wnt signals. J Clinl Invest 2005;115:1210-1220. 